promote increased opportunities for active and safe play engagement for children with ASD.

\section{SOCIAL IMPACT ON LOWER LIMB DISABILITY AMONG URBAN COMMUNITY DWELLING RESIDENTS IN SRI LANKA}

1,2Inoka Eranganie Weerasinghe, ${ }^{3}$ Pushpa Fonseka, ${ }^{4}$ Samath Dharmaratne, ${ }^{4}$ Sumedha Jayatilake. 'Ministry of Health, Sri Lanka; ${ }^{2} J o h n s$ Hopkins Centre for Injury Research and Policy, Johns Hopkins Bloomberg School of Public Health, Johns Hopkins University, Baltimore, USA; ${ }^{3}$ University of Sri Jayawardanapura, Sri Lanka; ${ }^{4}$ University of Peradeniya, Sri Lanka

\subsection{6/injuryprev-2016-042156.360}

Background Social impact refers to changes in the ways in which people live, work, relate to one another, organise to meet their needs and their cultural norms and beliefs. Disability is often a perception created by social environment. Therefore, physically disabled people are more vulnerable and suffer more due to societal prejudices than due to health conditions. Present study explored the social impact due to limb disability in terms of attitudes among a group of city dwelling residents in Sri Lanka.

Methods A qualitative research was conducted using in-depth interviews to extract data on social impact associated with unilateral limb disability in year 2012. A sample of persons with unilateral lower limb disability $(n=12)$ were selected from a major study to assess the physical disability in a selected population in central Sri Lanka. An interviewer guide prepared on a conceptual framework was used to extract information from in-depth interviews.

Results People had different attitudes and behaviours towards the limb disabled. Participants described several enacted, perceived and internalised stigma experiences such as being criticised and isolated by the community, health providers, friends and relatives as well as denial of access to education and meaningful work roles. Some people helped and consoled the limb disabled. Some participants had feelings of discrimination by the society especially in conditions of disfigurement. Non acceptance of the social sympathy on one's disability status was demonstrated by several participants. Lack of safety and accessibility facilities confined them to their residential facilities.

Conclusions Implementation of safety and accessibility facilities, community awareness programmes and improvement of social attitudes associated with limb disability depending on the age, gender and education are necessary for Sri Lanka.

\section{Parallel Sessions Wednesday 21.9.} 8:30-10:00

\section{Rural and Agricultural Safety}

\section{Parallel Wed 1.1}

\section{A POPULATION-BASED STUDY OF ALL-TERRAIN VEHICLE EXPOSURE IN A RURAL COUNTY}

Gerene Denning, Justin Chau, Karisa Harland, Charles Jennissen. Department of Emergency Medicine, University of lowa Carver College of Medicine, USA

10.1136/injuryprev-2016-042156.361
Background All-terrain vehicle (ATV) crashes are common in agricultural communities, but few studies have reported on who is being exposed and may be at greatest injury risk. This study was performed to determine the epidemiology of ATV exposure and crashes in a rural county.

Methods Data was analysed from the Keokuk County Rural Health study which is a prospective population-based, longitudinal study of residents in Keokuk County, Iowa. Descriptive and comparative analyses were performed on 2006 Round 3 survey data which included ATV-related questions.

Results Of 1,123 respondents, 38\% reported having ridden an ATV in the previous year. Respondents who were male, younger, currently working on a farm, had higher income, or owned/ rented more acres had a greater likelihood of recent ATV exposure. Adults with children in the home were more likely to have ridden an ATV in the past year than those with none $(53 \%$ vs. $28 \%, \mathrm{p}<0.0001)$. ATV exposure also varied by place of residence, with $57 \%$ of those living on a farm being exposed vs. $20 \%$ of those living in town $(\mathrm{p}<0.0001)$. Respondents who were working on farms had the highest exposure rates $(75 \%)$. Those 12-19 years of age, with taxable household income < $\$ 60,000$, and adults who had never been married were each significantly more likely to have experienced an "ATV wreck" in the previous year. Of adults, 92\% never wore a helmet when riding an ATV with "don't own a helmet" the most common reason (43\%). Ten percent reported having been injured on an ATV in the past with more than one-half requiring medical attention. Previous safety training was reported by only $14 \%$ of adults having had ATV exposure in the past year.

Conclusions Study respondents had a high exposure to ATVs, particularly young people and those who lived or worked on farms. Safety training efforts should be focused on demographic groups identified with higher exposure and greater likelihood of ATV crash, including agricultural workers and their families.

\section{GENDER DIFFERENCES IN WORK TASKS AND INJURIES IN AGRICULTURE}

${ }^{1}$ Janne P Karttunen, ${ }^{2}$ Risto H Rautiainen. ${ }^{1} T T S$ Work Efficiency Institute, Finland; ${ }^{2}$ University of Nebraska Medical Centre, USA

\subsection{6/injuryprev-2016-042156.362}

Background Research indicates that farmers in general and livestock farmers in particular have an elevated risk of work-related adverse health outcomes. We investigated gender differences in work tasks and occupational injuries in the Finnish farming population covered by the mandatory workers' compensation insurance.

Methods Insurance claims data were augmented with data from a postal survey containing questions about the relative division of farm work between male and female farmers.

Results Over the 5-year study period (2009-2013), the average number of farmers was 73,870 (males $67 \%$ and females 33\%) with a total of 23,004 compensated occupational injuries (males $75 \%$ and females 25\%). Claims most frequently involved work tasks related to animal husbandry. Altogether 319 usable responses were received to the postal survey (12.9\% response rate). Farm work time and occupational injuries differed by gender. In general, crop production, construction work, forestry work, and few other farm work tasks including repair and maintenance of machines, and farmstead and road maintenance were male-dominated, whereas females took the main responsibility 
for domestic work and caretaking work. Animal husbandry was divided more evenly between males and females with their relative work contributions of $56 \%$ and $44 \%$, respectively. Animal husbandry-related injuries were divided correspondingly between the genders (males 57\% and females 43\%) but all other types of injuries occurred mostly to males.

Conclusions While many studies have shown that male farmers have a much greater risk of injury than females, our study shows that given equal work time, the risk of injury was also equal. Therefore, rather than a risk factor, gender is an indicator of different work exposures in farming. This finding suggests that targeting interventions to males is still appropriate, but it is more important to target the underlying hazardous work tasks and exposures as they increase the injury risk of both males and females.

\section{USING THE SOCIO-ECOLOGIC MODEL AS A GUIDE FOR AGRICULTURAL SAFETY INTERVENTIONS}

Barbara C Lee, Marsha Salzwedel, Bryan Weichelt, Casper Bendixsen. National Children's Centre for Rural and Agricultural Health and Safety, Marshfield, WI, USA

\subsection{6/injuryprev-2016-042156.363}

Background Agriculture is a dangerous industry that allows children in the worksite. Each day about 38 children are seriously injured on farms. The culture of agriculture resists advice from outsiders. Farm operators/parents prefer receiving information from familiar sources, not safety professionals. The Socio-ecologic Model (SEM) demonstrates how spheres of increasing influence have higher degrees of impact on individual behaviour.

Methods We modified the SEM to have farm children as the focal point, with adults/parents the first line of protection. Increasing spheres of influence are family and friends, followed by the community, organisations, and businesses. Public policy has the greatest influence but in agriculture rarely applies. Key farm business contacts are property and liability insurance providers. We conducted a study to assess if and how insurers could influence farmers regarding childhood farm safety. Surveys were distributed at a farm risk management training with 96 (55\%) insurers responding.

Results Agricultural insurers reported 55\% currently send general safety information and 38\% provide financial support of safety events. Regarding child-specific information, 79\% want to increase their focus on children and $63 \%$ need guidance for this. Furthermore, $76 \%$ believe customers would be pleased if they added a focus on childhood farm safety. Using these results, an illustrated report was sent to 150 agricultural insurance companies. It highlighted safety topics of concern, including ATVs and children operating tractors. Details were offered on insurance providers' strategies, such as co-branding farm safety posters, updating farm policies on young workers, and website links to and evidence-based programs.

Conclusions This new approach may influence farmers to protect children from preventable injuries. The project impact, including numbers and types of actions taken by insurance companies, will be shared at the Safety 2016 World Conference.

\section{DISABLING FARM INJURIES AND SAFETY INTERVENTIONS: AN INDIAN STUDY}

Adarsh Kumar, JK Singh. Indian Agricultural Research Institute, New Delhi, India

\subsection{6/injuryprev-2016-042156.364}

Background 260 million perons are associated with farm activities in India. Aaccording to Census 2011, a total of 26.8 million persons are disable. There is an increase of 5 million in last 10 years, indicating an addition of 1400 disabled individual every day. In agricultural "acquired disability" because of unsafe farm machine injuries is an added dimension to rural disability.

Methods: Compensation data of agricultural injury victims (156 cases) were collected from the Sonipat District, Haryana, India to assess kind of injuries and disabilities along with machines associated for the years 2008 to 2014. The most common machines associated with disabling injury was fodder cutter, safety interventions were developed and retrofitted in 50 households and feedback was collected.

Results Total bodily injuries were 105 out of 156 cases, out of which 84 cases $(80 \%)$ pertains to amputation of fingers, 13 cases involved and wrist (12\%), 5 cases (5\%) had leg injury, one person (1\%) injured his eye and four cases (4\%) injuries sustained on upper body. Machines associated with injuries were chaff cutters (74 cases), electric motors (20 cases), tube wells (6 cases), threshers (12 cases), tractor/trolley (9 cases), harrows ( 2 cases), and one each of reaper, sickle, winnower, and seed drill. The causal factor associated with fodder cutter injuries were; accessibility of children to machine, get injured while playfully interacting with this machine; hands injuries while feeding the fodder as entrapped in the rollers; diverted attention; loose clothes, get entangles in the gears and belt.

Conclusions Simple safety gadgets consisting of blade guard, flywheel lock, warning roller were developed and retrofitted in rural households and feedback suggested that it prevents injuries but some farmers of the opinion that warning roller hinders feeding of fodder quickly.

\section{BATTLEFIELD TO FARM FIELD: RISK PERCEPTIONS OF US MILITARY VETERANS TRANSITIONING INTO AGRICULTURE}

Casper G Bendixsen, Kathrine Barnes, Bryan Weichelt, Jeff VanWormer, Matthew C Keifer Marshfield Clinic Research Foundation, USA.

\subsection{6/injuryprev-2016-042156.365}

Background Prompted by wars in the past two decades largely in the Middle East, the United States veteran population in the United States often struggles with unemployment. America is increasingly occupied by the mental health ramifications of deployment. Domestically, the United States grapples with securing a healthy and abundant food source to support a large food insecure population in the midst of decreases in the number of farms and increasing food imports. The veteran-to-farmer (V2F) movement converges within these two concerns to provide jobs and potential therapeutic benefits to veterans through food production.

Methods The project combines a grounded theory approach with epidemiology to understand a broad range of implications for the V2F movement. Grounded theory will be utilised to conduct semi-structured interviews and participant-observation to explore 